\title{
PENGARUH RIWAYAT MELAHIRKAN BAYI LEBIH DARI 4000 GRAM TERHADAP KEJADIAN DIABETES MELITUS TIPE 2 PADA WANITA USIA SUBUR DI WILAYAH KERJA PUSKESMAS PINTUPADANG KABUPATEN TAPANULI SELATAN
}

\author{
Lisna Khairani Nasution \\ Stikes Darmais Padangsidimpuan \\ Email: ranyie09.nastyie@gmail.com
}

\begin{abstract}
ABSTRAK
Diabetes Melitusmerupakanpenyakitkronis yang disebabkan oleh ketidakmampuan tubuh untuk memproduksi hormon insulin atau karena penggunaan yang tidak efektif dari hormon itu. Hal ini ditandai dengan tingginya kadar gula dalam darah. DM menduduki peringkat ke 6 sebagai penyebab kematian di dunia. Penelitianinibertujuanuntuk mengetahui faktor-faktor yang memengaruhi kejadian DM tipe 2 pada WUS di Wilayah Kerja Puskesmas Pintupadang. Penelitian ini merupakan penelitian analitik observasional dengan desain kasus kontrol dimana sampel kasus dan kontrol berjumlah 62 orang. Metode analisis data yang digunakan adalah analisis bivariat dengan uji chi square. Hasil penelitian menunjukkan bahwa tidak ada pengaruh riwayat melahirkan bayi $>4000$ gram dengan kejadian DM tipe 2 pada WUS dengan nilai $(\mathrm{p}=1,000 ; \mathrm{OR}=1,193 ; 95 \% \mathrm{CI}=0,37-3,82)$. Adapun saran bagi Petugas Kesehatan di Puskesmas agar dapat meningkatkan pelayanan secara optimal terutama dalam memberikan berbagai pengetahuan tentang cara pengendalian kadar glukosa darah sehingga jumlah penderita DM tipe 2 dapat diturunkan dan bagi Masyarakat Umum (Wanita Usia Subur) khususnya yang memiliki riwayat keluarga DM sehingga dapat mengurangi peyumbangan Angka Kematian Bayi (AKB) dan Angka Kematian Ibu (AKI).
\end{abstract}

Kata Kunci: DM Tipe 2; WUS; riwayat melahirkan bayi

\begin{abstract}
Diabetes mellitus (DM) is a chronic disease caused by the incapability of the body to produce insulin hormone or by the ineffective use that hormone. It is indicated by the high level of glucose in blood. It ranks the sixth as the cause of death throughout the world. The objective of the research was to find out some factors influencing the incidence of DM Type 2 in RAW (reproductive age women) in the working area of Puskesmas Pintupadang. The research used observational analytic method with case-control design of 62 respondents. The data were analyzed by using bivariate analysis with Chi-square test. The result showed that there was noinfluence of thehistory of giving birth to babies with > 4,000 grams on the incidence of DM Type 2 in $R A W(p=1,000 ; O R=1,193 ; 95 \% C I=0,37-3,82)$. There are suggestions for health workers at the health center so that they can improve services optimally, especially in providing various knowledge about how to control blood glucose levels so that the number of people with type 2 diabetes can be reduced and for the general public (women of fertile age) especially those who have a family history of diabetes so that it can reduce the contribution of the Infant Mortality Rate (IMR) and the Maternal Mortality Rate (MMR).
\end{abstract}

Keywords: DM Type 2; history of Childbirth; reproductive age women

\section{PENDAHULUAN}

Menurut World Health Organization (WHO) 60\% penyebab kematian semua umur di dunia adalah karena Penyakit Tidak Menular (PTM). Diabetes Melitus merupakan PTM yang menduduki peringkat ke 6 sebagai penyebab kematian. Sekitar 1,3 juta orang meninggal akibat diabetes dan 4\% meninggal sebelum usia 70 tahun. Diabetes Melitus merupakan penyakit kronis yang terjadi apabila pankreas tidak menghasilkan insulin yang adekuat atau ketika tubuh tidak dapat secara efektif menggunakan insulin yang diproduksinya. Hal ini mengakibatkan terjadinya peningkatan konsentrasi glukosa dalam darah yang dikenal dengan istilah hiperglikemia. 
Jika dilihat dari faktor risiko, wanita lebih berisiko mengidap diabetes karena secara fisik wanita memiliki peluang peningkatan indeks masa tubuh yang lebih besar. Sindroma siklus bulanan (premenstrual syndrome) dan pasca-menopouse yang membuat distribusi lemak tubuh menjadi mudah terakumulasi. Selain itu, pada wanita yang sedang hamil terjadi ketidakseimbangan hormonal. Hormon progesteron menjadi tinggi sehingga meningkatkan sistem kerja tubuh untuk merangsang sel-sel berkembang, sehingga terjadi peningkatan kadar gula darah saat kehamilan. Akibat proses hormonal tersebut sehingga wanita berisiko menderita Diabetes Melitus tipe 2 (Irawan, 2010).

Wanita Usia Subur (WUS) adalah wanita dengan usia 15-49 tahun. Pada usia subur, organ reproduksi wanita sudah matang dan berfungsi dengan baik. Puncak kesuburan wanita terjadi pada rentang usia 20-29 tahun. Wanita memiliki risiko yang cukup besar terhadap Diabates Melitus Tipe 2. Selain itu, ada faktor risiko Diabetes Melitus Tipe 2 yang sangat melekat pada wanita yakni riwayat Diabetes Gestasional atau riwayat pernah melahirkan bayi dengan berat $>4.000$ gram (Kemenkes, 2015).

Komplikasi Diabetes Melitus pada masa kehamilan adalah abortus dan partus prematur, PreEklamsia, Hydramnion, Kelainan letak janin karena janin besar, Insufiensi plasenta. Penyulit dalam persalinan pada penderita Diabetes Melitus adalah Inersia uteri dan atonia uteri, distosia bahu karena anak besar, kelahiran mati, lebih sering pengahiran partus dengan tindakan , termasuk operasi Sectio Cesaria, lebih mudah terjadi infeksi, angka kematian maternal lebih tinggi (Rukiyah, 2010).

WHO memperkirakan pada tahun 2030 Diabetes Melitus menempati urutan ke 7 penyebab kematian didunia. Prevalensi DM tertinggi terdapat di wilayah Mediterania Timur (14\%) dan terendah di Eropa dan wilayah Pasifik Barat (8\% - 9\%). Menurut estimasi IDF (2014) 8,3\% penduduk di seluruh dunia mengalami DM, prevalensi ini meningkat dari tahun 2011 yaitu 7,0\% dan diprediksikan pada tahun 2035 prevalensi DM akan meningkat menjadi 10,0\%. Dalam Diabetes Atlas edisi ke enam tahun 2014 yang dikeluarkan oleh International Diabetes Federation (IDF). Jumlah penderita DM semakin bertambah, diperkirakan proporsi penderita DM yang tidak terdiagnosis adalah sebesar $46,3 \%$.

Menurut American Diabetes Association (ADA) (2014) prevalensi penderita DM di Amerika adalah sebesar 9,3\%, meningkat dari tahun 2010 yaitu sebanyak 25,8 juta jiwa, dimana 8,1 juta orang penderita tersebut tidak terdiagnosis. Insidens DM pada tahun 2012 adalah sebanyak 1,7 juta jiwa. Penyakit ini merupakan ke tujuh penyebab utama kematian di Amerika pada tahun 2010. Berdasarkan hasil Riset Kesehatan Dasar (2013), Prevalensi penderita DM berdasarkan wawancara (pernah di diagnosid dokter dan ada gejala) menunjukkan bahwa terjadi peningkatan prevalensi diabetes melitus yaitu dari 1,1\% pada tahun 2007 menjadi 2,1\% pada tahun 2013 .

Dari 33 provinsi di indonesia memperlihatkan adanya kenaikan prevalensi DM yang cukup berarti.Prevalensi tertinggi DM pada umur >15 tahun pada tahun 2013 adalah provinsi Sulawesi Tengah $(3,7 \%)$,Sulawesi Utara (3,6\%), Sulawesi Selatan $(3,4 \%)$. Nusa Tenggara Timur $(3,3 \%)$, dan yang terendah adalah di Provinsi Lampung (0,8\%).( Balitbangkes, 2013).

Berdasarkan hasil penelitian Wahyuni, 2012 dengan menggunakan data Riskesdas persentase DM pada perempuan usia reproduksi (15-49 tahun) adalah 3,6\%. Hal ini perlu diwaspadai sebab wanita dengan DM memiliki risiko untuk melahirkan bayi besar, hal tersebut sejalan dengan hasil penelitian Oroh, Dkk (2013), dengan nilai Odds Ratio sebesar 1,532 sehingga dapat dikatakan 
bahwa diabetes melitus gestasional merupakan faktor resiko dari makrosomia, sedangkan menurut hasil penelitian Setiawan, Dkk (2014) menunjukkan tidak terdapat hubungan antara Diabetes Melitus gestational dengan makrosomia (nilai p 0,301). Hasil Riskesdas tahun 2007 berdasarkan kabupaten/kota di Sumatera Utara prevalensi penderita DM terbanyak terdapat di Kabupaten Pakpak Barat sebesar 1,6\% diikuti Kota Medan dan Kota Tebing Tinggi yaitu masing-masing 1,5\% (Balitbangkes, 2013).

Puskesmas Pintupadang merupakan puskesmas rawat inap di Kabupaten Tapanuli Selatan.Pada tahun 2015 jumlah penderita diagnosis DM pada Wanita Usia Subur adalah 49 orang atau 3,9\% dari 1.234 Wanita Usia Subur dan mengalami peningkatan pada tahun 2016 menjadi 73 orang atau 5,2\% dari 1.410 Wanita Usia Subur. Hal tersebut menunjukkan terjadi peningkatan kejadian Diabetes Melitus pada WUS dari tahun ke tahun.

Berdasarkan latar belakang di atas maka peneliti tertarik untuk melakukan penelitian tentang "Pengaruh Riwayat Melahirkan Bayi Lebih Dari 4000 Gram Terhadap Kejadian Diabetes Melitus Tipe 2 PadaWanitaUsia Subur Di wilayah Kerja Puskesmas Pintu padang Kabupaten Tapanuli Selatan"

\section{METODE PENELITIAN}

Jenis penelitian yang digunakan adalah studi analitik observasional dengan desain penelitian casecontrol dilakukan di wilayah kerja Puskesmas Pintupadang dengan menggunakan data primer dan sekunder. Populasi dalam penelitian ini adalah semua WUS yang menderita DM Tipe 2 yang datang ke bagian penyakit tidak menular di wilayah kerja Puskesmas Pintupadang.

Variabel yang diamati dalam penelitian ini adalah riwayat melahirkan bayi $>4000$ gram, riwayat keluarga DM dan obesitas. Metode analisis data yang digunakan meliputi analisis univariat, analisis bivariat dengan chi-square. Waktu penelitian ini dimulai dari bulan Februari s/d bulan Agustus 2017.

\section{HASIL DAN PEMBAHASAN} Analisis Univariat

Tabel 1 Karakteristik WUS di Wilayah Kerja Puskesmas Pintupadang Kabupaten Tapanuli Selatan

\begin{tabular}{lcccc}
\multicolumn{1}{c}{ Karakteristik WUS } & \multicolumn{2}{c}{ Kelompok Kasus } & \multicolumn{2}{c}{ Kelompok Kontrol } \\
\cline { 2 - 5 } & $\mathbf{n}$ & $\mathbf{\%}$ & $\mathbf{n}$ & \% \\
\hline Umur & & & & \\
$15-32$ & 7 & 22,6 & 15 & 48,4 \\
$33-49$ & 25 & 80,6 & 16 & 51,6 \\
Pekerjaan & & & & \\
Tidak Bekerja & 19 & 61,3 & 20 & 64,5 \\
Bekerja & 12 & 38,7 & 11 & 35,5 \\
Pendidikan Terakhir & & & & \\
SD /MI & 14 & 45,2 & 12 & 38,7 \\
SMP / MTs & 10 & 32,3 & 8 & 25,8 \\
SMA/ SMK / MA & 5 & 16 & 7 & 22,6 \\
PT & 2 & 6,5 & 4 & 12,9 \\
Pengetahuan & & & & \\
Kurang & 26 & 83,8 & 21 & 67,7 \\
Baik & 5 & 16,2 & 10 & 32,3 \\
\hline Total & 31 & 100,0 & 31 & 100,0 \\
\hline
\end{tabular}


Berdasarkan Tabel 1 diketahui bahwa WUS yang mengalami Diabetes Melitus Tipe 2 mayoritas berumur 32 - 49 tahun $(80,6 \%)$ pada kelompok kasus dan kontrol, pada kelompok kasus mayoritas WUS tidak bekerja atau sebagai ibu rumah tangga sebanyak 19 orang $(61,3 \%)$ sedangkan pada kelompok kontrol lebih banyak WUS yang bekerja sebanyak 20 orang (64,5\%). Pendidikan terakhir WUS mayoritas SD/MI pada kelompok kasus 14 orang $(45,2 \%)$ dan pada kelompok kontrol sebanyak 12 orang (38,7 \%), pengetahuan ibu masyoritas masih kurang pada kelompok kasus 26 orang $(83,8 \%)$ dan pada kelompok kontrol 21 orang $(67,7 \%)$.

Tabel 2 Distribusi Variabel Independen terhadap Kejadian DM tipe 2 Di Wilayah Kerja Puskesmas Pintupadang Kabupaten Tapanuli Selatan

\begin{tabular}{cccccc}
\hline Variabel Independen & \multicolumn{3}{c}{ Kasus } & \multicolumn{2}{c}{ Kontrol } \\
\cline { 2 - 5 } & $\mathbf{n = 3 1}$ & $\mathbf{( \% )}$ & $\mathbf{n = 3 1}$ & $\mathbf{\%}$ \\
\hline Riwayat Melahirkan Bayi $>\mathbf{4 0 0 0}$ & grm & & & & 22,6 \\
Ya (Berisiko) & 8 & 25,8 & 7 & 77,4 \\
Tidak (Tidak Berisiko) & 23 & 74,2 & 24 & \\
\hline
\end{tabular}

Berdasarkan Tabel 1 diketahui WUS pada kelompok kasus dengan Riwayat Melahirkan Bayi $>4000$ gram berisiko sebanyak 8 orang $(25,8 \%)$, WUS pada kelompok kontrol dengan Riwayat Melahirkan Bayi $>4000$ tidak berisiko sebanyak 24 orang $(77,4 \%)$.

\section{Analisis Bivariat}

Tabel 2 Distribusi Riwayat Melahirkan Bayi >4000 Gram Terhadap Kejadian Diabetes Melitus Tipe 2 Pada WUS di Wilayah Kerja Puskesmas Pintupadang Tapanuli Selatan

\begin{tabular}{lllll}
\hline \multirow{2}{*}{ Variabel Independen } & \multicolumn{2}{l}{ Kejadian Diabetes Melitus Tipe 2 } & OR \\
\cline { 2 - 3 } & \multicolumn{2}{l}{ Kasus } & Kontrol & $P$ CI)
\end{tabular}

\begin{tabular}{lccllll}
\hline \multicolumn{6}{l}{ Riwayat Melahirkan Bayi $>4000$} & Gram \\
Berisiko & 8 & 25,8 & 7 & 22,6 & 1,193 & \\
Tidak Berisiko & 23 & 74,2 & 24 & 77,4 & $(0,372-3,821)$ & 1,000 \\
\hline
\end{tabular}

Berdasarkan Tabel 2 menunjukkan bahwa tidak ada pengaruh antara riwayat melahirkan bayi $>4000$ gram dengan kejadian DM tipe 2 pada WUS dengan nilai $\mathrm{p}=1,000(\mathrm{p}<0,05)$, dengan nilai OR sebesar 1,193 (95\% CI :0,372 - 3,821).

\section{Pengaruh Riwayat Melahirkan Bayi >4000 Gram Bayi terhadap Kejadian DM Tipe 2 Pada WUS}

Hasil penelitian tentang riwayat melahirkan bayi >4000 gram diperoleh bahwa WUS yang memiliki riwayat melahirkan bayi $>4000$ gram (berisiko) tidak jauh berbeda antara kelompok kasus dan kelompok kontrol, pada kelompok kasus 25,0 \% dan pada kelompok kontrol 22,6 \% sedangkan pada WUS yang tidak memiliki riwayat melahirkan bayi >4000 gram pada kelompok kasus sebanyak 23 orang $(74,2 \%)$ dan pada kelompok kontrol yaitu sebanyak 24 orang $(77,4 \%)$.

Hasil uji statistik menunjukkan bahwa tidak ada pengaruh antara riwayat melahirkan bayi $>4000$ gram dengan kejadian DM tipe 2 pada WUS dengan nilai $\mathrm{p}=1,000(\mathrm{p}<0,05)$, dengan nilai OR sebesar 1,193 (95\% CI :0,372 - 3,821). Penelitian ini menunjukkan bahwa riwayat melahirkan 
bayi >4000 gram merupakan faktor penyebab kejadian DM tipe 2 pada WUS tetapi tidak berpengaruh terhadap kejadian DM tipe 2 pada WUS.

Hal ini sesuai dengan hasil penelitian penelitian Setiawan (2014) yang menunjukkan bahwa tidak terdapat pengaruh antara Diabetes Melitus gestational dengan makrosomia (nilai p 0,301),dan bertolak belakang dengan hasil penelitian Oroh, Dkk (2013), dengan nilai Odds Ratio sebesar 1,532 sehingga dapat dikatakan bahwa diabetes melitus gestasional merupakan faktor penyebab dari makrosomia.

Dari analisis tambahan diketahui bahwa WUS yang memiliki pengetahuan baik tentang dampak Diabetes Melitus terhadap kesehatan reproduksi masih sangat rendah, pada kelompok kasus 16,5 $\%$ sedangkan pada kelompok kontrol 32,3\% yang berpengetahuan baik, Sedangkan WUS yang berpengetahuan tidak baik menjadi mayoritas pada kelompok kasus dan kontrol, pengetahuan ibu terhadap dampak Diabetes Melitus terhadap Kesehatan Reproduksi ini perlu ditingkatkan karena begitu banyak dampak yang bisa dihindari.

\section{KESIMPULAN DAN SARAN}

Berdasarkan hasil penelitian di Wilayah Kerja Puskesmas Pintupadang Kabupaten Tapanuli Selatan menunjukkan bahwa variabel riwayat melahirkan bayi $>4000$ gram tidak berpengaruh terhadap kejadian DM tipe 2 pada WUS.

Adapun saran bagi Petugas Kesehatan di Puskesmas agar dapat meningkatkan pelayanan secara optimal terutama dalam memberikan berbagai pengetahuan tentang cara pengendalian kadar glukosa darah sehingga jumlah penderita DM tipe 2 dapat diturunkan dan bagi Masyarakat Umum (Wanita Usia Subur) khususnya yang memiliki riwayat keluarga DM sehingga dapat mengurangi peyumbangan Angka Kematian Bayi (AKB) dan Angka Kematian Ibu (AKI).

\section{DAFTAR PUSTAKA}

American DiabetesAssociation (ADA), (2014). Diabetes Statistic. http://www.diabetes.org. Diakses Tanggal 12 Februari 2017.

Balitbangkes. (2013). Riset Kesehatan Dasar 2013. http://www.depkes.go.id.Diakses Tanggal 12 Februari 2017.

IDF (2014). IDF Diabetes Atlas Sixth Edition. http://www.idf.org. Diakses Tanggal 12 Februari 2017.

Irawan, D. (2010). Prevalensi dan Faktor Risiko Kejadian Diabetes Melitus Tipe 2 di Daerah Urban Indonesia (Analisa Data Sekunder Riskesdas 2007). Tesis. Depok: FKM UI.

Kemenkes RI. (2015). Pusat Data dan Informasi Kesehatan Penyakit Tidak Menular.Jakarta : Kemenkes RI.

Oroh,A., Loho.M., Mongan.S., (2015). Kaitan Makrosomia Dengan Diabetes Melitus Gestasional Di Bagian Obsgin Blu Rsup Prof. Dr. R. D. Kandou. FKM USR.

Riset Kesehatan Dasar (2013), Badan Penelitian dan Pengembangan Kesehatan Dasar Departemen Kesehatan Republik Indonesia.

Rukiyah, Yeyeh A.., Yulianti, L. (2010). Asuhan Kebidanan 4 (Patologi Kebidanan). Jakarta: Trans Info Medika

Setiawan, H., Fratidhina, Y., Ali, M. (2014). Hubungan Ibu Hamil Pengidap Diabetes Melitus Dengan Kelahiran Bayi Makrosomia Di RSAB Harapan Kita Jakarta, poltekkesjakarta3.ac.id 
Wahyuni, S., Alkaff., R. (2012). Diabetes Melitus Pada Wanita Usia Produktif di Indonseia Tahun 2007. Jakarta : FKM dan FK UIN Syarif Hidayahtullah.

WHO. (2014). Global Status Report On Non Communicable Diseases 2014. Diakses 12 Februari 2017. 